\title{
Crystal Growth of ZnO Microneedles in Water Containing Microbubbles
}

\author{
Yomei Tokuda ${ }^{*}$, Hiroaki Matsuki ${ }^{1}$, Yoshikatsu Ueda' ${ }^{2}$, Hirokazu Masai ${ }^{1}$, Toshinobu Yoko ${ }^{1}$ \\ ${ }^{1}$ Institute for Chemical Research, Kyoto University, Kyoto, Japan \\ ${ }^{2}$ Research Institute for Sustainable Humanosphere, Kyoto University, Kyoto, Japan \\ Email: tokuda@noncry.kuicr.kyoto-u.ac.jp
}

Received 20 May 2014; revised 15 June 2014; accepted 10 July 2014

Copyright (C) 2014 by authors and Scientific Research Publishing Inc.

This work is licensed under the Creative Commons Attribution International License (CC BY).

http://creativecommons.org/licenses/by/4.0/

c) (i) Open Access

\begin{abstract}
Microbubble technology is now available in a wide range of industrial fields. The liquid containing microbubbles possesses a large number of air-liquid interfaces, and also generates radicals during bubble collapse. Here, we synthesized $\mathrm{ZnO}$ powder to explore the potential of microbubbles as starting materials for the formation of crystalline micro- or nanoparticles. The bubbles facilitated the growth of ZnO microneedles in high yields, and enhanced the reaction by radicals generated on bubble collapsing.
\end{abstract}

\section{Keywords}

Microbubble, Microcrystal, ZnO

\section{Introduction}

Microbubbles are defined as having diameters less than $50 \mu \mathrm{m}$, and have important technical applications in industrial fields [1]-[3]. Although the characteristics of water that contains microbubbles are not completely understood [3]-[5], such water is currently used in semiconductor plants to remove oil [6] and on Japanese highways to remove de-icing salts [7].

Microbubbles can be generated in water by various methods. One of the most efficient methods for producing fine bubbles, such as nano- or microbubbles, involves centrifugal gas-liquid separation [8], in which a mixture of gas and liquid is rotated at a high rotational velocity. The gas bubbles in the liquid are fractured because of the centrifugal shearing force during rotation. Advantages of this method include the generation of bubbles of $\sim 100$ $\mathrm{nm}$ in diameters and the long-term stability [9]. Additionally, the gas-liquid shearing method is versatile because any gas and liquid can be used as starting materials.

*Corresponding author.

How to cite this paper: Tokuda, Y., Matsuki, H., Ueda, Y., Masai, H. and Yoko, T. (2014) Crystal Growth of ZnO Microneedles in Water Containing Microbubbles. New Journal of Glass and Ceramics, 4, 49-54. 
Microbubbles tend to decrease in size due to the dissolution of their interior gas into the surrounding water, and to collapse due to the high interior gas pressure on collapsing. Free radicals are generated from the bubbles even in the absence of ultrasound waves. These free radicals are known to accelerate chemical reactions. Indeed, the radicals generated by cavitation are used in sonochemistry [10]. Moreover, such radicals have affected the crystal growth of $\mathrm{ZnO}$ [11], in which $\mathrm{ZnO}$ nanorods were aligned on a substrate. On the other hand, it was expected that microbubbles could act as crystal nuclei for the heterogeneous nucleation because of the high interfacial surface area between the bubbles and the liquid. From the view point of crystal growth, the advantage of using microbubble nucleation would be the absence of residue in the final product.

A preparative approach employing microbubbles would constitute a novel preparation method for nanomaterials. However, no reports are presently available. Here, we synthesize $\mathrm{ZnO}$ microcrystals using water containing microbubbles (MB water), in order to demonstrate its potential in the field of nanomaterials.

\section{Experimental Section}

MB water was prepared by the centrifugal gas-liquid separation method (BUVITAS HYK-32-D, Ligaric, Japan [7]. Distilled water $(11 \mathrm{~L})$ at a flow rate of $45 \mathrm{~L} / \mathrm{min}$ and gas at a rate of $0.7 \mathrm{~L} / \mathrm{min}$ were subjected to centrifugal rotation for 90 min to afford $\mathrm{MB}$ water. The gases used in this study were $\mathrm{N}_{2}$ and $\mathrm{O}_{3}$; the latter was generated by UV irradiation of oxygen gas (EO-OG-R4, Ecodesign-labo, Japan). It should be noted that $\mathrm{O}_{3} \mathrm{MB}$ water contains both $\mathrm{O}_{2}$ and $\mathrm{O}_{3}$ gases.

The concentration of ozone in $\mathrm{O}_{3} \mathrm{MB}$ water was determined by the difference in the $\mathrm{UV}$ absorption between the purified and ozonated water (ozone densitometer OZM 5000G, Okitrotec Co. Ltd., Japan).

The size distributions of the gas bubbles in the purified and MB waters were characterized using a laser-illuminated optical microscopic technique based on particle-tracking analysis (NanoSight LM10, NanoSight, Ltd.) [12]. The detection limit ranged from 50 to $1000 \mathrm{~nm}$, depending on the particles and solvent.

All chemical reagents were used without further purification. Solutions of $\mathrm{Zn}\left(\mathrm{NO}_{3}\right)_{2}(25 \mathrm{mM})$ and of hexamethylenetetramine (HMT, $25 \mathrm{mM}$ ) were prepared using different water medium (purified water without bubbles for comparison, $\mathrm{N}_{2} \mathrm{MB}$ water, or $\mathrm{O}_{3} \mathrm{MB}$ water), $\mathrm{Zn}\left(\mathrm{NO}_{3}\right)_{2}$ (Wako Pure Chemicals Industries, Ltd., Japan), and HMT (Wako Pure Chemicals Industries, Ltd., Japan). A mixture of $\mathrm{Zn}\left(\mathrm{NO}_{3}\right)_{2}$ solution (50 mL) and HMT solution $\left(50 \mathrm{~mL}\right.$ ) was stirred for $90 \mathrm{~min}$ at $90^{\circ} \mathrm{C}$ to produce a precipitate. Microparticles were collected on a Si substrate by dipcoating.

Scanning electron microscopy (SEM) images were obtained for the microparticles using a field-emission scanning electron microscope (JSM6500F, JEOL, Japan). X-ray diffraction (XRD) patterns were also obtained for the precipitate (RINT-2000, Rigaku, Japan).

\section{Results and Discussion}

Figure 1 and Figure 2 show the time dependence of the mode values of the diameter and the bubble concentration $\left(10^{8}\right.$ particles $\left./ \mathrm{mL}\right)$ at the mode value of the diameter, respectively. The error bars indicate the standard dev-

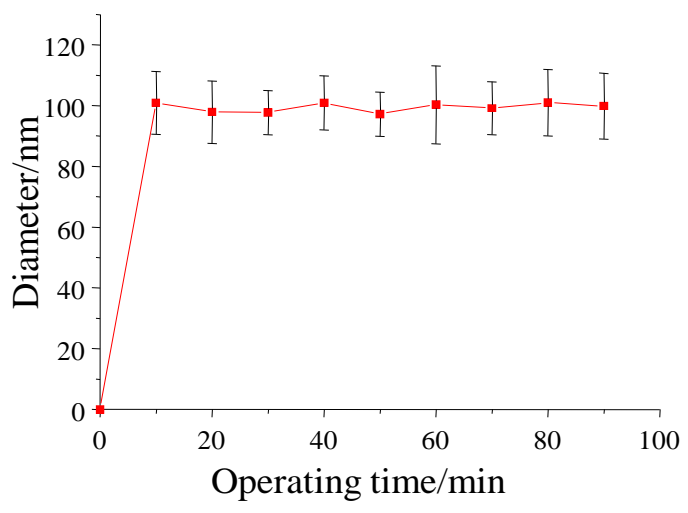

Figure 1. Mode value of the $\mathrm{N}_{2}$ bubble diameter versus centrifugal gas-liquid separation time. The error bars indicate the standard deviation over seven experiments. 


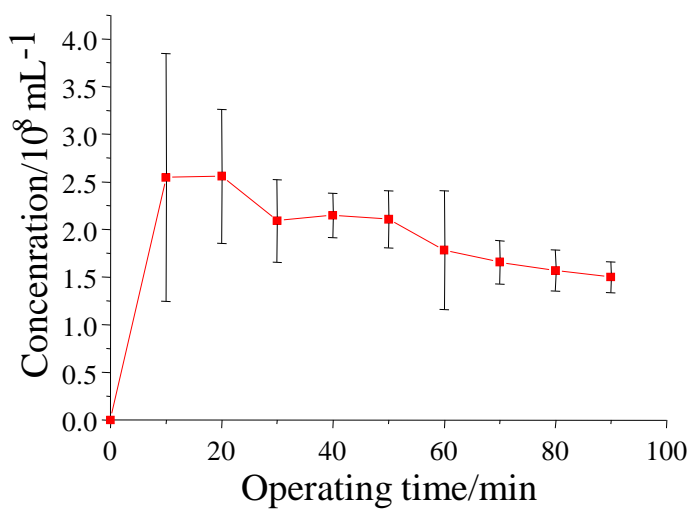

Figure 2. Bubble concentration $\left(10^{8}\right.$ particles $\left./ \mathrm{mL}\right)$ at the mode values of the diameter for $\mathrm{N}_{2} \mathrm{MB}$ water versus centrifugal gas-liquid separation time. The error bars indicate the standard deviation for over seven experiments.

iation over seven repetitions. The bubbles in the water were determined to be microbubbles of $\sim 100 \mathrm{~nm}$ in diameter after 10 min operation. The standard deviation of the concentration before 30 min was rather large, but became small after $30 \mathrm{~min}$. Moreover, over $50 \mathrm{~min}$, the concentration decreased due to the heat generated by the centrifugal apparatus. Therefore, because of the stability of both the diameter and concentration, $\mathrm{N}_{2}$ microbubble (MB) water centrifugally rotated for 50 min was used for the preparation of $\mathrm{ZnO}$.

In the case of $\mathrm{O}_{3} \mathrm{MB}$ water, the bubble diameters showed similar behavior to the $\mathrm{N}_{2} \mathrm{MB}$ water. However, the ozone concentration reached a maximum and then decreased after $\sim 30$ min (Figure 3). This was also due to the heat generated by the centrifugal apparatus, because the ozone spontaneously decomposed above room temperature. Therefore, because of the stability of the concentration, $\mathrm{O}_{3} \mathrm{MB}$ water operated for $50 \mathrm{~min}$ was used for the preparation of $\mathrm{ZnO}$.

Table 1 shows the reaction yields of $\mathrm{ZnO}$ together with the bubble concentrations, the maximum bubble diameter values, and the ozone concentration. The $\mathrm{ZnO}$ yields obtained from purified water, $\mathrm{N}_{2} \mathrm{MB}$ water, and $\mathrm{O}_{3}$ MB water were $0.11,0.35$, and 0.60 , respectively. Thus, the yield was increased by using the MB waters instead of pure water, and the $\mathrm{O}_{3} \mathrm{MB}$ water produced a much higher yield than the $\mathrm{N}_{2} \mathrm{MB}$ water.

The increase in the yield through the use of MB water can be interpreted based on the growth mechanism of ZnO nanorods as follows [13]-[15],

$$
\begin{gathered}
\left(\mathrm{CH}_{2}\right)_{6} \mathrm{~N}_{4}+6 \mathrm{H}_{2} \mathrm{O} \rightarrow 4 \mathrm{NH}_{3}+6 \mathrm{HCHO} \\
\mathrm{NH}_{3}+\mathrm{H}_{2} \mathrm{O} \rightarrow \mathrm{NH}_{4}^{+}+\mathrm{OH}^{-} \\
\mathrm{Zn}^{2+}+2 \mathrm{OH}^{-} \rightarrow \mathrm{ZnO}+\mathrm{H}_{2} \mathrm{O}
\end{gathered}
$$

In the case of MB water, Reaction (3) was expected to be enhanced due to the increased interfacial surface area between the bubbles and water.

In the case of $\mathrm{O}_{3} \mathrm{MB}$ water, the increment can be also interpreted based on the generation of radicals on $\mathrm{O}_{3}$ decomposition. That is, ozone decomposes to generate free radicals as follows [16],

$$
\begin{gathered}
\mathrm{O}_{3}+\mathrm{OH}^{-} \rightarrow \mathrm{HO}_{2}^{-}+\mathrm{O}_{2} \\
\mathrm{O}_{3}+\mathrm{HO}_{2}^{-} \rightarrow \mathrm{HO} \bullet+\bullet \mathrm{O}_{2}^{-}+\mathrm{O}_{2}
\end{gathered}
$$

where the symbol "•" indicates the radical. The generated radical reacts with $\mathrm{Zn}^{2+}$ to produce $\mathrm{ZnO}$ as follows [11],

$$
\mathrm{Zn}^{2+}+2 \bullet \mathrm{O}_{2}^{-} \rightarrow \mathrm{ZnO}+3 / 2 \mathrm{O}_{2}
$$

$\mathrm{XRD}$ measurements were carried out to examine whether the microbubbles affected the $\mathrm{ZnO}$ crystal structure or not. Figure 4 shows XRD patterns of $\mathrm{ZnO}$ prepared using purified water, $\mathrm{N}_{2} \mathrm{MB}$ water, and $\mathrm{O}_{3} \mathrm{MB}$ water, 


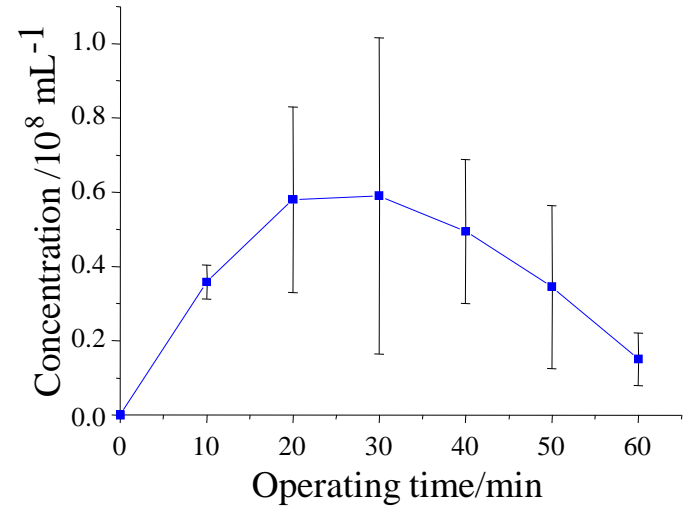

Figure 3. Aqueous ozone concentration in water plotted against the operation time. The error bars indicate the standard deviation for over seven experiments.

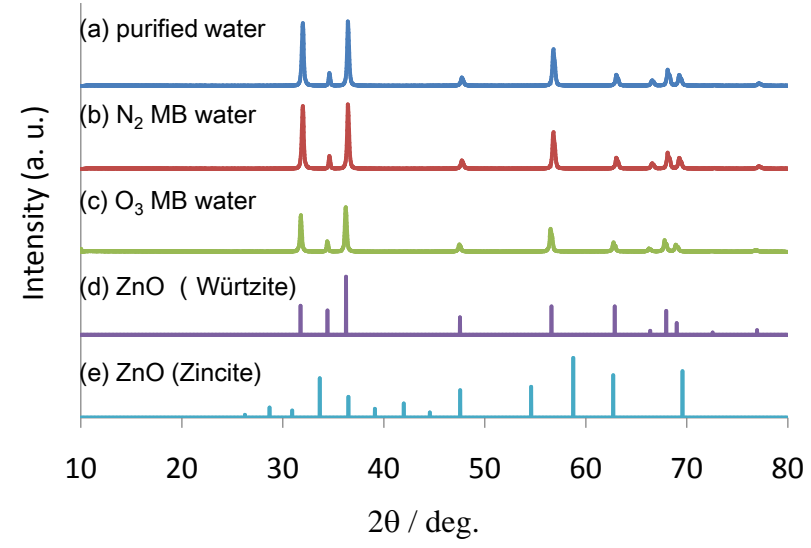

Figure 4. XRD patterns of $\mathrm{ZnO}$ prepared with (a) purified water, (b) $\mathrm{N}_{2} \mathrm{MB}$ water, or (c) $\mathrm{O}_{3} \mathrm{MB}$ water, together with $\mathrm{XRD}$ patterns derived from the JCPDS database.

Table 1. Bubble concentration, mode value of the diameter, ozone concentration, and reaction yields.

\begin{tabular}{|c|c|c|c|}
\hline & \multirow{2}{*}{ Purified water } & \multicolumn{2}{|c|}{ MB water } \\
\hline & & $\mathrm{N}_{2}$ & $\mathrm{O}_{3}$ \\
\hline Bubble concentration $/ 10^{8} \mathrm{~mL}^{-1}$ & 0 & 1.64 & 0.88 \\
\hline Bubble diameter/nm & - & 103 & 135 \\
\hline Aqueous ozone concentration/mgL $\mathrm{mL}^{-1}$ & - & - & 3.19 \\
\hline yield $\left([\mathrm{ZnO}] /\left[\mathrm{Zn}\left(\mathrm{NO}_{3}\right)_{2}\right]\right)$ & 0.11 & 0.35 & 0.6 \\
\hline
\end{tabular}

together with the powder diffraction patterns of wurtzite and zincite from the JCPDS database. The results clearly showed that there were no differences among the samples. Hence, neither the interfacial surfaces nor the radicals had distinct effect on the crystal structure of $\mathrm{ZnO}$.

Finally, SEM observations were carried out to determine the effects of the microbubbles on the sizes or shapes of $\mathrm{ZnO}$ crystals (Figure 5). From purified water, the island-shaped $\mathrm{ZnO}$ crystals were grown, while in the cases of water with microbubbles, the $\mathrm{ZnO}$ crystals in needle-like structures of $\sim 1 \mu \mathrm{m}$ in length were grown. Note that purified water has no interfacial surfaces in the reaction system. As a result, the mechanism of crystal growth is mainly due to homogeneous nucleation. The number of initial crystallites is small, which results in large crystals and a low reaction yield. On the other hand, in the MB water, a lot of interfacial surfaces are present in the reac- 


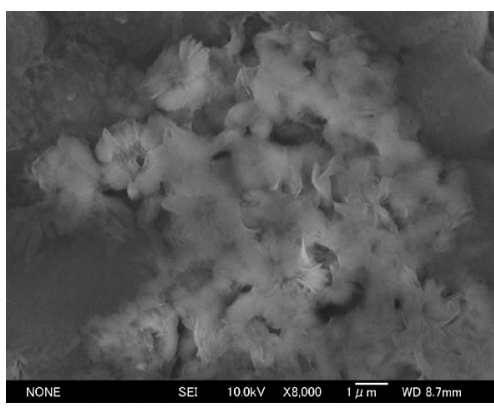

(a)

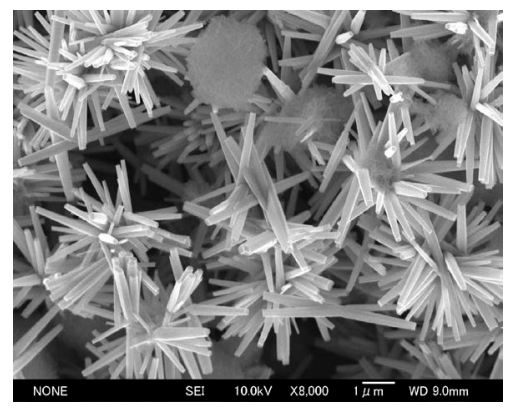

(b)

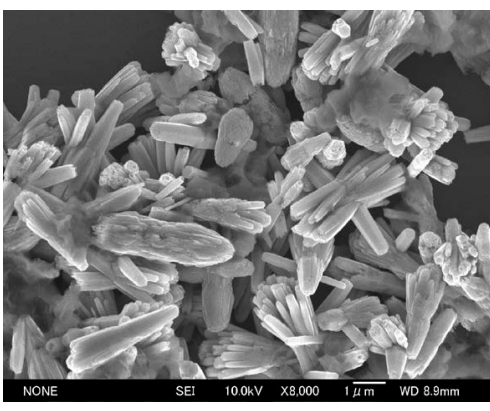

(c)

Figure 5. SEM images of $\mathrm{ZnO}$ prepared with (a) purified water, (b) $\mathrm{N}_{2} \mathrm{MB}$ water, and (c) $\mathrm{O}_{3} \mathrm{MB}$ water.

tion system, which acts as nuclei for heterogeneous nucleation. The number of $\mathrm{ZnO}$ crystallites is expected to be large. Accordingly, the concentration of $\mathrm{Zn}^{2+}$ decreased rapidly, resulting in small crystals and high yields. In addition, from $\mathrm{O}_{3} \mathrm{MB}$ water, $\mathrm{ZnO}$ crystals with low aspect ratio were grown, while in the case of $\mathrm{N}_{2} \mathrm{MB}$ water, that with high aspect ratio. We believe that this result is due to the enhancement of the oxidation reaction by $\mathrm{O}_{3}$.

\section{Conclusions}

$\mathrm{ZnO}$ crystals were grown from purified water, $\mathrm{N}_{2} \mathrm{MB}$ water, and $\mathrm{O}_{3} \mathrm{MB}$ water mediums. On the basis of the yield, crystal structure, and crystal shape, we reviewed whether the presence of the bubbles and radicals affected crystal growth. The yields in the experiments that used MB water were larger than in those that used purified water. We believe that this increment by means of $\mathrm{MB}$ water was due to the presence of interfacial surfaces between the bubbles and water, which acted as nuclei for heterogeneous nucleation. $\mathrm{O}_{3} \mathrm{MB}$ water provided a higher yield than $\mathrm{N}_{2} \mathrm{MB}$ water. This increment was likely due to the radicals generated by $\mathrm{O}_{3}$. The use of MB water resulted in the formation of $\mathrm{ZnO}$ with needle-like structures of $\sim 1 \mu \mathrm{m}$ in length, whereas that of purified water produced islandshaped $\mathrm{ZnO}$. This result was also interpreted as being due to heterogeneous nucleation: the concentration of $\mathrm{Zn}^{2+}$ decreased rapidly, resulting in small crystals. On the other hand, the crystal structures were identical and independent of the presence of MB in the initial water. Thus, MB water is a potential and novel starting material for the facile preparation of microcrystals.

We have presented a simple and facile method for producing $\mathrm{ZnO}$ microneedles using water containing microbubbles. In the reaction system, the interfaces between the bubbles and water are expected to promote heterogeneous nucleation. In addition, the radicals generated on the collapse of $\mathrm{O}_{3}$ bubbles can be used as oxidizing agents. We expect that the present process can also be applied to the synthesis of other types of oxide nano- or microparticles because we can select any gas as inert, oxidative or reductive gas for preparing bubbles.

\section{Acknowledgements}

This work was supported by the Center for Exploratory Research on Humanosphere of the Research Institute for Humanosphere, Kyoto University. This work was also financially supported by a Grant-in-Aid for Scientific Research, No. 20613007 and Mazda Foundation.

\section{References}

[1] Burns, S.E., Yiacoumi, S. and Tsouris, C. (1997) Microbubble Generation for Environmental and Industrial Separations. Separation and Purification Technology, 11, 221-232. http://dx.doi.org/10.1016/S1383-5866(97)00024-5

[2] Kodama, Y., Kakugawa, A., Takahashi, T. and Kawashima, H. (2000) Experimental Study on Microbubbles and Their Applicability to Ships for Skin Friction Reduction. International Journal of Heat and Fluid Flow, 21, 582-588. http://dx.doi.org/10.1016/S0142-727X(00)00048-5

[3] Agarwal, A., Ng, W.J. and Liu, Y. (2011) Principle and Applications of Microbubble and Nanobubble Technology for Water Treatment. Chemosphere, 84, 1175-1180. http://dx.doi.org/10.1016/j.chemosphere.2011.05.054

[4] Takahashi, M. (2005) $\zeta$ Potential of Microbubbles in Aqueous Solutions: Electrical Properties of the Gas-Water Interface. The Journal of Physical Chemistry B, 109, 21858-21864. http://dx.doi.org/10.1021/jp0445270

[5] Takahashi, M., Izawa, E., Etou, J. and Ohtani, T. (2002) Kinetic Characteristic of Bubble Nucleation in Superheated 
Water Using Fluid Inclusions. Journal of the Physical Society of Japan, 71, 2174-2177. http://dx.doi.org/10.1143/JPSJ.71.2174

[6] Miyamoto, T.U.M. (2010) Japanese Patent, 4595764.

[7] Yamazaki, Y. (2012) Japanese Patent, 4916526.

[8] Tsuji, H. (2008) Japanese Patent, 4118939.

[9] Ueda, Y., Tokuda, Y., Shigeto, F., Nihei, N. and Oka, T. (2013) Removal of Radioactive Cs from Gravel Conglomerate Using Water Containing Air Bubbles. Water Science and Technology, 67, 996-999. http://dx.doi.org/10.2166/wst.2013.650

[10] Bang, J.H. and Suslick, K.S. (2007) Sonochemical Synthesis of Nanosized Hollow Hematite. Journal of the American Chemical Society, 129, 2242.

[11] Jung, S.H., Oh, E., Lee, K.H., Park, W. and Jeong, S.H. (2007) A Sonochemical Method for Fabricating Aligned ZnO Nanorods. Advanced Materials, 19, 749.

[12] Gallego-Urrea, J.A., Tuoriniemi, J. and Hassellov, M. (2011) Applications of Particle-Tracking Analysis to the Determination of Size Distributions and Concentrations of Nanoparticles in Environmental, Biological and Food Samples. TrAC Trends in Analytical Chemistry, 30, 473-483. http://dx.doi.org/10.1016/j.trac.2011.01.005

[13] Hu, X.L., Zhu, Y.J. and Wang, S.W. (2004) Sonochemical and Microwave-Assisted Synthesis of Linked Single-Crystalline ZnO Rods. Materials Chemistry and Physics, 88, 421-426. http://dx.doi.org/10.1016/j.matchemphys.2004.08.010

[14] Li, W.J., Shi, E.W., Zhong, W.Z. and Yin, Z.W. (1999) Growth Mechanism and Growth Habit of Oxide Crystals. Journal of Crystal Growth, 203, 186-196. http://dx.doi.org/10.1016/S0022-0248(99)00076-7

[15] Chaparro, A.M., Maffiotte, C., Gutierrez, M.T. and Herrero, J. (2003) Study of the Spontaneous Growth of ZnO Thin Films from Aqueous Solutions. Thin Solid Films, 431, 373-377. http://dx.doi.org/10.1016/S0040-6090(03)00248-7

[16] Gurol, M.D. and Akata, A. (1996) Kinetics of Ozone Photolysis in Aqueous Solution. AIChE Journal, 42, 3283-3292. http://dx.doi.org/10.1002/aic.690421128 
Scientific Research Publishing (SCIRP) is one of the largest Open Access journal publishers. It is currently publishing more than 200 open access, online, peer-reviewed journals covering a wide range of academic disciplines. SCIRP serves the worldwide academic communities and contributes to the progress and application of science with its publication.

Other selected journals from SCIRP are listed as below. Submit your manuscript to us via either submit@scirp.org or Online Submission Portal.
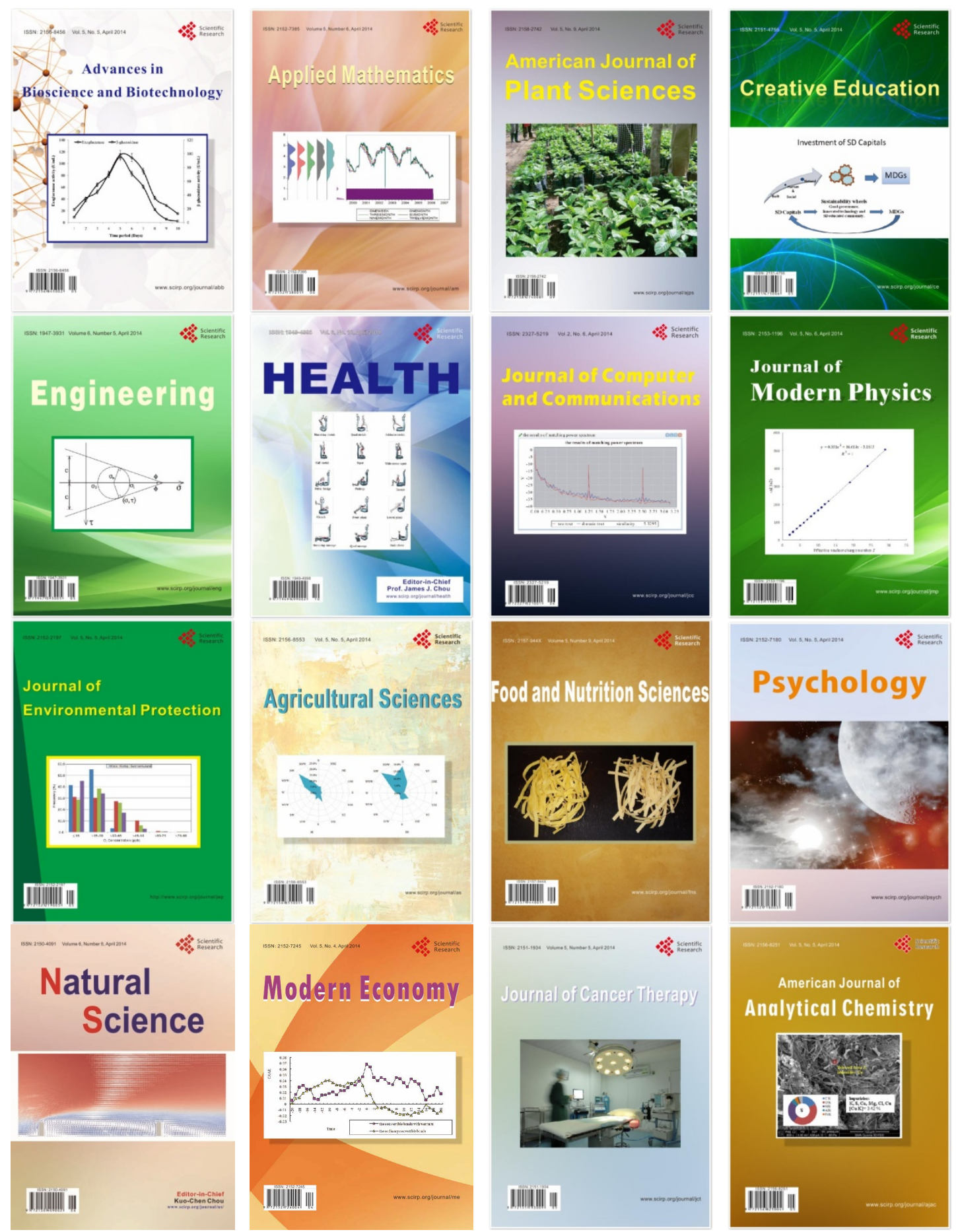